\title{
Aberrant fetal growth and development after in vitro culture of sheep zygotes
}

\author{
K. D. Sinclair ${ }^{1}$, T. G. McEvoy ${ }^{1}$, E. K. Maxfield ${ }^{2}$, C. A. Maltin'2, L. E. Young ${ }^{3}$, I. Wilmut ${ }^{3}$, \\ P. J. Broadbent ${ }^{1}$ and J. J. Robinson ${ }^{1}$
}

${ }^{1}$ Scottish Agricultural College, Craibstone Estate, Bucksburn, Aberdeen AB21 9YA, UK; ${ }^{2}$ Rowett Research Institute, Greenburn Road, Bucksburn, Aberdeen AB21 9SB, UK; and ${ }^{3}$ Roslin Institute, Roslin, Midlothian EH25 9PS, UK

\begin{abstract}
The effects of in vitro culture systems for sheep zygotes on subsequent fetal growth and development to day 61 and day 125 of gestation were studied. Zygotes recovered from superovulated Scottish Blackface ewes approximately $36 \mathrm{~h}$ after intrauterine insemination using semen from a single Suffolk sire were cultured for 5 days in (a) a granulosa cell co-culture system (co-culture); (b) synthetic oviductal fluid medium without serum (SOF-); and (c) synthetic oviductal fluid medium supplemented with human serum $(\mathrm{SOF}+)$. Control embryos were recovered from superovulated donor ewes at day 6 after oestrus. Embryos were transferred at day 6 to synchronous Scottish Blackface recipient ewes. In total, 146 gravid uteri were recovered, comprising 97 at day 61 (20 co-culture, 27 SOF-, $25 \mathrm{SOF}+$ and 25 control) and 49 at day 125 (13 co-culture, $8 \mathrm{SOF}-, 6 \mathrm{SOF}+$ and 22 control) of gestation. Fetuses derived from co-cultured embryos were $14 \%$ heavier $(P<0.01)$ by day 61 of gestation than those derived from control embryos. Growth coefficients derived from the linear allometric equation $\log _{e} y=\log _{e} a+$ $b \log _{e} x$ (where $y=$ organ mass; $x=$ fetal mass) were significantly greater $(P<0.05)$ for liver, heart, kidneys and plantaris muscle in fetuses derived from co-cultured embryos, and for liver in fetuses derived from SOF+ embryos than those for control fetuses. Fetuses derived from co-cultured embryos were $34 \%$ heavier $(P<0.001)$ and fetuses derived from SOF+ embryos were $18 \%$ heavier $(P<0.01)$ by day 125 of gestation than those derived from control embryos. Growth coefficients for liver and heart for fetuses derived from co-culture and SOF+ embryos were also significantly greater $(P<0.05)$ at this stage of gestation than those for control group fetuses. In contrast, allometric coefficients for these organs in fetuses derived from embryos cultured in SOF without serum supplementation were not different from those for controls. Excessive volumes of amniotic fluid (polyhydramnios) were observed in $23 \%$ of conceptuses derived from co-cultured embryos. In vitro embryo culture can significantly influence fetal growth and this study provides quantitative evidence of major shifts in the patterns of organ and tissue development.
\end{abstract}

\section{Introduction}

Advanced reproductive technologies can deliver substantial benefits to livestock production through their ability to increase the rate of genetic gain within genetic improvement programmes and to enhance the rate of dissemination of improved genetic material (Woolliams and Wilmut, 1989; Brash et al., 1996; Sinclair and Broadbent, 1996). New industries are being generated on the basis of the production of transgenic animals with the ability, for example, to produce novel proteins for use in human medicine (Wilmut and Whitelaw, 1994). An integral part of these new technologies is in vitro embryo culture. However, reports of unusually large

Received 21 September 1998. offspring in ruminants after the transfer to recipients of embryos cloned by nuclear transfer or cultured in vitro, with associated complications at birth resulting in high perinatal morbidity and mortality (for review, see Walker et al., 1996; Kruip and den Daas, 1997; Young et al., 1998), are impeding the adoption of such technologies in these species.

Field-scale trials with cattle have provided quantitative information on the effects on birth weight of nuclear transfer (Willadsen et al., 1991; Wilson et al., 1995) and in vitro embryo production (Hasler et al., 1995; van Wagtendonk-de Leeuw et al., 1998). However, to date, information on fetal development has been largely anecdotal with detailed physical, physiological and metabolic studies being limited to the neonate (Garry et al., 1996). The gross changes described are sporadic in their incidence and may disguise 
more subtle but fundamental shifts in organ and tissue development than have been reported. These developmental shifts may occur at a much higher frequency and could, in addition to influencing neonatal morbidity and mortality, impinge on postnatal growth and longevity. Therefore, the purpose of this study was to describe any such changes in the growth and development of sheep fetuses derived from in vitro cultured embryos.

\section{Materials and Methods}

The experiment described in this paper was reviewed by the Animals and Welfare Committees of the Scottish Agricultural College and was conducted under the auspices of, and in accordance with the requirements of, the Home Office Animals (Scientific Procedures) Act, 1986.

\section{Animals and experimental design}

Mature Scottish Blackface ewes, with no overt disease or reproductive abnormalities, were assembled in August 1995 and assigned randomly to be either zygote donors, embryo donors or recipients. The donor ewes were superovulated and artificially inseminated using semen from the single Suffolk sire used by Sinclair et al. (1998). Zygotes recovered from these donors were cultured in vitro for 5 days on one of three treatments: (a) a granulosa cell co-culture system (coculture); (b) unsupplemented synthetic oviductal fluid medium (SOF-); or (c) synthetic oviductal fluid medium supplemented with serum (SOF+). Control embryos were recovered from superovulated donor ewes at day 6 after oestrus (day 0). All embryos were transferred singly at day 6 to synchronous recipients. Gravid uteri were recovered at day 61 and day 125 of gestation.

\section{Embryo production and transfer}

Oestrous cycles were synchronized in both donor and recipient ewes using progestogen-releasing intravaginal sponges (30 mg fluorogestone acetate, Chronogest, Intervet, Cambridge) for 12 days. For recipient ewes, the same sponge remained in position for 12 days whereas, for donor ewes, it was removed and a second sponge was inserted after 7 days. Recipients received $400 \mathrm{iu}$ pregnant mares' serum gonadotrophin (Intervet, Cambridge) at sponge withdrawal. Oestrous observations began $24 \mathrm{~h}$ after progestogen withdrawal and were carried out at 08:00, 12:00, 16:00 and 24:00 h during the next 3 days, using raddled vasectomized rams.

Superovulation was induced in donor ewes using a total dose of $9 \mathrm{mg}$ oFSH (Ovagen, ICP Ltd, Auckland) administered twice daily in equal doses over 4 days beginning on day 10 of the 12 day progestogen priming period. Laparoscopic intrauterine insemination was carried out $44 \mathrm{~h}$ after sponge withdrawal using fresh semen from a single Suffolk sire diluted 1:3 in PBS containing 1000 iu sodium penicillin and $1 \mathrm{mg}$ streptomycin sulphate $\mathrm{ml}^{-1}$. The diluted semen was held at $30^{\circ} \mathrm{C}$ before insemination and approximately $100 \times 10^{6}$ motile spermatozoa were placed in each uterine horn.

Zygotes were collected during mid-ventral laparotomy after induction of general anaesthesia (halothane; oxygen; nitrous oxide) $36-42 \mathrm{~h}$ after insemination. Each oviduct was flushed with $20 \mathrm{ml}$ Hepes-buffered synthetic oviductal fluid, derived from the formulation of Tervit et al. (1972), and containing $20.0 \mathrm{mmol}$ Hepes buffer $\mathrm{l}^{-1}$ (pH 7.4), $5.0 \mathrm{mmol}$ sodium bicarbonate $\mathrm{l}^{-1}, 1.5 \mathrm{mmol}$ glucose $\mathrm{l}^{-1}, 3.3 \mathrm{mmol}$ sodium lactate $\mathrm{l}^{-1}, 0.33 \mathrm{mmol}$ sodium pyruvate $\mathrm{l}^{-1}, 1.0 \mathrm{mmol} \mathrm{L-}$ glutamine $1^{-1}$ and $30 \mathrm{mg}$ bovine serum albumin $\mathrm{ml}^{-1}$. All zygotes with normal morphology were allocated to one of three culture systems. Allocation to treatments aimed to ensure that, in so far as zygote yields permitted, each donor and each stage of development (range $=1$-cell to 4-cell) were represented equally across treatments, thus avoiding any pre-culture bias.

The co-culture medium used was M199 with Earle's salts (Life Technologies, Paisley) together with $50 \mathrm{iu}$ penicillin $\mathrm{ml}^{-1}, 50 \mu \mathrm{g}$ streptomycin sulphate $\mathrm{ml}^{-1}$ and $10 \%(\mathrm{v} / \mathrm{v})$ heatinactivated $\left(56^{\circ} \mathrm{C} ; 30 \mathrm{~min}\right.$ ) steer serum (Globepharm Ltd, Esher). The medium was at pH 7.3 and 290-310 mOsm. Both SOF media, derived from the original formulation of Tervit et al. (1972) and excluding Hepes buffer, included $25.0 \mathrm{mmol}$ sodium bicarbonate $\mathrm{l}^{-1}, 9.9 \mathrm{mmol}$ sodium lactate $\mathrm{l}^{-1}$, $0.99 \mathrm{mmol}$ sodium pyruvate $1^{-1}, 1.5 \mathrm{mmol}_{\text {glucose }} \mathrm{l}^{-1}, 1.0 \mathrm{mmol}$ L-glutamine $\mathrm{l}^{-1}, 50 \mathrm{iu}$ penicillin $\mathrm{ml}^{-1}$ and $50 \mu \mathrm{g}$ streptomycin sulphate $\mathrm{ml}^{-1}$. SOF- also contained $1 \%(\mathrm{v} / \mathrm{v})$ non-essential amino acids (catalogue number M7145; Sigma, Poole) and 2\% (v/v) essential amino acid (catalogue number B6766; Sigma) solutions, together with $0.4 \%(\mathrm{w} / \mathrm{v})$ bovine serum albumin (catalogue number 81-001; Miles Pentex; Bayer Diagnostics, Basingstoke). In contrast, $\mathrm{SOF}+$ was supplemented with heat-inactivated human serum to form a $20 \%(\mathrm{v} / \mathrm{v})$ serum culture medium. Both media were at pH 7.4 and 270-280 mOsm.

In the co-culture treatment, up to four day 1 zygotes were introduced to 3-day-old bovine granulosa cell layers, which had been established previously in $50 \mu \mathrm{l}$ droplets of coculture medium placed in tissue culture dishes $(60 \mathrm{~mm}$ diameter; Bibby Sterilin, Stone) overlaid with mineral oil (catalogue number M8410; Sigma). The culture medium was refreshed (50\% replacement, by volume) just before the zygotes were introduced and thereafter at $48 \mathrm{~h}$ intervals during the culture period, which proceeded for 5 days in a humidified atmosphere $\left(5 \% \mathrm{CO}_{2}, 95 \%\right.$ air $)$ at $38.5^{\circ} \mathrm{C}$.

Cell- and serum-free SOF- droplets and cell-free but serum-supplemented SOF+ droplets, each of $20 \mu 1$ under oil, were prepared (eight droplets per culture dish) on the day of zygote collection. Up to four zygotes were cultured per SOFor $\mathrm{SOF}+$ drop in a reduced-oxygen humified atmosphere $(5 \%$ $\mathrm{CO}_{2}, 5 \% \mathrm{O}_{2}, 90 \% \mathrm{~N}_{2}$ ) at $38.5^{\circ} \mathrm{C}$. At $48 \mathrm{~h}$ intervals thereafter, zygotes were moved to freshly prepared $20 \mu \mathrm{l}$ droplets incubated in identical conditions.

Steer serum was used to supplement co-culture media because in a small scale trial it was observed that this culture system resulted in fetal oversize in sheep after transfer of embryos cultured from in vivo produced zygotes. This culture 
system also produced oversize in large scale cattle field trials involving embryos produced totally in vitro from abattoirderived oocytes. The SOF medium was supplemented with human serum because Walker et al. (1992a) consistently observed fetal oversize when in vivo produced sheep zygotes were cultured in this medium-serum combination and the resultant embryos were transferred. There was insufficient evidence to show whether the culture system, the type of serum or both the culture system and serum were the causative factors resulting in fetal oversize. Consequently, the two systems with their respective serum supplements were tested in the present study.

On day 6 of culture, morula and blastocyst stage embryos with quality grades 1 to $3(1=$ excellent, $5=$ degenerate; Lindner and Wright, 1983) were removed from their respective culture environments, placed into ovum culture medium (catalogue number 1-150-07; Imperial Laboratories, Andover), and promptly transferred to the waiting recipient ewe. Day 6 in vivo or in vitro produced embryos were transferred singly to recipient ewes. Transfer of an embryo was preceded by induction of general anaesthesia in the recipient. The transfer technique involved temporary exposure of the tip of the uterine horn through a small ventral incision of the abdominal wall by laparoscopically-guided pickup (McMillan and Hall, 1994).

\section{Conceptus recovery}

Pregnancy was determined at days 55-60 of gestation by transabdominal ultrasound examination. Pregnant recipient ewes were killed at day 61 and day 125 of gestation by i.v. administration of $25 \mathrm{ml} 20 \%(\mathrm{w} / \mathrm{v})$ pentobarbitone sodium (Euthatal, Rhône Mérieux Ltd, Harlow) and bled from the main vessels of the neck. The gravid uterus of each ewe was then recovered and weighed. The fetus was removed, weighed and its curved crown-rump length measured. Fetal membranes, cotyledons and uterine caruncles were separated and weighed. Viscera, including the liver, heart and kidneys, and individual plantaris and tibialis anterior muscles were excised and weighed, and the humerus length was measured.

\section{Data analysis}

Within and between treatment differences in blastocyst production and pregnancy rate were analysed using the chi-squared test. Differences in the mass of the products of conception, and of fetal organs and muscle tissue, and differences in humerus length among treatments at both day 61 and day 125 of gestation were analysed by the ANOVA directive within GENSTAT 5 (Genstat, 1993). The sex ratio of the fetuses, the stages of development and grades of embryos from which the fetuses were derived did not differ significantly among the treatments and, therefore, these factors were not included in the final statistical model. Data are presented as simple means \pm SEM.

During normal growth, the fetus, its organs and tissues increase in size and mass at different rates. Consequently, larger fetuses, which are developing normally but at a faster rate, will have different proportions of each body part and component to those of smaller fetuses, which are developing normally but at a slower rate. Therefore, if growth is perturbed but the proportions of each organ and tissue are commensurate with those observed in an animal of the same size that has been achieved by normal growth, then development is normal. However, if the proportion of a body component does not show the relationship to body size associated with normal growth, then development is altered.

The relationship between body size (growth) and proportions of organs and tissues (development) can be assessed using the allometric equation of Huxley (1932) $y=$ a $x^{b}$ (where $y=$ the mass of the organ or tissue, $x=$ the mass of the whole body, $b$ is the organ or tissue growth coefficient, and $\mathrm{a}$ is a constant). Where the values of $b$ differ from those observed during normal growth, then the fundamental patterns of development have been altered and the differences in body proportions are not the same as those observed during normal growth. In the present study, the allometric equation was used in its linear form: $\log _{y} y=$ $\log _{i} a+b \log _{i} x$, to assess fetal development at day 61 and day 125 and the values for the allometric growth coefficient (b) of fetuses derived from cultured embryos were compared with those observed during normal growth from the data of Sinclair et al. (1998).

\section{Results}

Overall blastocyst production on day 6 from in vivo produced zygotes (1-4-cell stages) was $28.9 \%, 13.2 \%$ and $28.3 \%$ (chi-squared $=29.8 ; \mathrm{df}=2 ; P<0.001$ ), and the proportions of grade 1 and 2 embryos produced from zygotes were $13.5 \%$, $6.4 \%$ and $10.7 \%$ (chi-squared $=9.484 ; \mathrm{df}=2, P<0.01$ ) from coculture, SOF- and SOF+, respectively. In contrast, $73.4 \%$ of in vivo embryos recovered at day 6 were blastocysts and $82.3 \%$ of embryos recovered were graded 1 and 2 . Morula stage embryos as a percentage of morulae plus blastocysts transferred were: co-culture, $44.7 \%$; SOF-, 27.4\%; SOF+, $40.0 \%$; and control, $11.2 \%$ (chi-squared $=26.9 ; \quad \mathrm{df}=3$; $P<0.001$ ). The proportion of grade 1 and 2 embryos among those transferred was also significantly different (co-culture, $42.0 \%$; SOF-, $27.1 \%$; SOF+, $29.2 \%$; control, $63.0 \%$; chi-squared $=30.5 ; \mathrm{df}=3 ; \mathrm{P}<0.001$ ) with a significant difference between co-culture and the two SOF treatments (chi-squared $=5.498$; $\mathrm{df}=1 ; P<0.05)$.

The proportion of fetuses produced as a consequence of transfer of a grade 1 or 2 embryo did not differ significantly among treatments (co-culture, 56.3\%; SOF-, 50.0\%; SOF+, 45.2\%; control, $57.4 \%$; chi-squared $=1.399$; $\mathrm{df}=3 ; \mathrm{P}>0.05$ ). The transfer of morulae resulted in fewer pregnancies $(13.7 \%)$ compared with the transfer of zona-intact unexpanded and expanded blastocysts $(55.5 \%$; chi-squared $=23.9 ; \mathrm{df}=1$; $P<0.001$; Table 1). The method of embryo production had no significant effect on the percentage of fetuses produced or of embryos transferred.

Pregnancy determination at days 55-60 meant that early pregnancy losses could not be observed and there were no losses from day 61 to day 125. In total, 146 fetuses were recovered, with 97 fetuses recovered at day 61 and 49 fetuses 
Table 1. Stage at transfer and pregnancy outcome at day 61 and day 125 of gestation for Suffolk $\times$ Scottish Blackface sheep embryos

\begin{tabular}{|c|c|c|c|c|c|c|c|c|c|c|}
\hline & \multicolumn{2}{|c|}{ Co-culture } & \multicolumn{2}{|c|}{ SOF- } & \multicolumn{2}{|c|}{$\mathrm{SOF}+$} & \multicolumn{2}{|c|}{ Control } & \multicolumn{2}{|c|}{ Total } \\
\hline & Transferred & Pregnant & Transferred & Pregnant & Transferred & Pregnant & Transferred & Pregnant & Transferred & Pregnan \\
\hline \multicolumn{11}{|l|}{ Embryo stage: } \\
\hline Morula & 34 & $\begin{array}{c}7 / 34 \\
(20.6 \%)\end{array}$ & 26 & $\begin{array}{c}1 / 26 \\
(3.8 \%)\end{array}$ & 32 & $\begin{array}{c}1 / 32 \\
(3.1 \%)\end{array}$ & 10 & $\begin{array}{c}5 / 10 \\
(50.0 \%)\end{array}$ & 102 & $\begin{array}{c}14 / 102 \\
(13.7 \%)\end{array}$ \\
\hline Blastocyst & 27 & $\begin{array}{c}19 / 27 \\
(70.4 \%)\end{array}$ & 42 & $\begin{array}{c}21 / 42 \\
(50.0 \%)\end{array}$ & 22 & $\begin{array}{c}14 / 22 \\
(63.6 \%)\end{array}$ & 21 & $\begin{array}{c}13 / 21 \\
(61.9 \%)\end{array}$ & 112 & $\begin{array}{l}67 / 112 \\
(59.8 \%)\end{array}$ \\
\hline \multicolumn{11}{|l|}{ Expanded } \\
\hline blastocyst & 15 & $\begin{array}{c}10 / 15 \\
(66.7 \%)\end{array}$ & 27 & $\begin{array}{c}10 / 27 \\
(37.0 \%)\end{array}$ & 26 & $\begin{array}{c}16 / 26 \\
(61.5 \%)\end{array}$ & 58 & $\begin{array}{c}29 / 58 \\
(50.0 \%)\end{array}$ & 126 & $\begin{array}{l}65 / 126 \\
(51.6 \%)\end{array}$ \\
\hline Total & 76 & $\begin{array}{c}36 / 76 \\
(47.4 \%)\end{array}$ & 95 & $\begin{array}{c}32 / 95 \\
(33.7 \%)\end{array}$ & 80 & $\begin{array}{c}31 / 80 \\
(38.8 \%)\end{array}$ & 89 & $\begin{array}{c}47 / 89 \\
(52.8 \%)\end{array}$ & 340 & $\begin{array}{l}146 / 340 \\
(42.9 \%)\end{array}$ \\
\hline
\end{tabular}

Co-culture: bovine granulosa cell layers with added serum; control: in vivo derived from superovulated donor ewes; SOF-: synthetic oviductal fluid medium without serum; SOF+: synthetic oviductal fluid medium supplemented with human serum.

Table 2. Products of conception (mean \pm SEM) at day 61 of gestation for Suffolk $\times$ Scottish Blackface sheep fetuses derived from day 6 in vivo produced embryos (controls) or day 6 in vitro produced embryos from in vivo produced zygotes

\begin{tabular}{lcccc}
\hline & Co-culture & SOF- & SOF+ & Control \\
\hline Number & 20 & 27 & 25 & 25 \\
Gravid uterus (g) & $1354 \pm 67$ & $1390 \pm 81$ & $1351 \pm 75$ & $1281 \pm 70$ \\
Fluids (g) & $530 \pm 66$ & $538 \pm 64$ & $555 \pm 56$ & $481 \pm 46$ \\
Chorioallantois $(\mathrm{g})^{*}$ & $419 \pm 26$ & $455 \pm 23$ & $413 \pm 20$ & $417 \pm 24$ \\
Uterus + caruncles $(\mathrm{g})$ & $320 \pm 15$ & $319 \pm 12$ & $307 \pm 10$ & $308 \pm 11$ \\
Fetal weight $(\mathrm{g})$ & $85.1 \pm 2.7^{\mathrm{b}}$ & $77.4 \pm 2.0^{\mathrm{a}}$ & $75.8 \pm 1.9^{\mathrm{a}}$ & $74.2 \pm 1.7^{\mathrm{a}}$ \\
Fetal CRL $(\mathrm{mm})$ & $162.4 \pm 2.2$ & $158.3 \pm 1.1$ & $158.3 \pm 1.3$ & $157.2 \pm 1.5$ \\
\hline
\end{tabular}

Means with different superscripts within rows are significantly different $(P<0.01)$.

*Includes amnion.

For description of treatments, see Table 1.

SOF-: synthetic oviductal fluid medium without serum; SOF+: synthetic oviductal fluid medium supplemented with human serum; CRL: curved crown-rump length.

recovered at day 125 of gestation. The overall fetal sex ratio was exactly 1:1, and there was no significant difference in this ratio among the experimental treatments. Male fetuses were approximately $5 \%$ heavier than female fetuses but this difference was not significant at either stage of gestation.

By day 61 of gestation, fetuses derived from co-culture embryos were, on average, $10.9 \mathrm{~g}$ or $14.7 \%$ heavier $(P<0.01)$ than fetuses derived from control embryos (Table 2), but those derived from embryos produced by the other two culture treatments were not significantly different from controls at this time point. Culture treatment had no significant effect on chorioallantois mass at day 61 of gestation. There was a weak but significant $(r=0.46 ; P<0.001)$ overall relationship between cotyledon mass and fetal mass at this time point.

Organ (liver, heart and kidneys) and muscle (plantaris and tibialis anterior) masses were significantly greater $(P<0.01)$ in fetuses derived from the co-culture treatment than in fetuses derived from the control treatment at day 61 of gestation (Table 3). Kidneys were also significantly heavier in fetuses derived from the SOF+ treatment than in controls $(1.20 \mathrm{~g}$ versus. $0.98 \mathrm{~g} ; P<0.05)$, but the tibialis anterior muscle was significantly lighter in SOF+ fetuses than in fetuses derived from the control treatment $(36.6 \mathrm{mg}$ versus $44.7 \mathrm{mg} ; P<0.05)$.

Allometric coefficients, relating component mass to fetal mass, were significantly greater $(P<0.05)$ for liver, heart, kidneys and plantaris muscle in fetuses derived from the co-culture treatment than for those components derived from control treatment; and were greater for liver in fetuses derived from $\mathrm{SOF}+$ than for liver derived from the control treatment (Table 4; Fig. 1).

At day 61 of gestation, the incidence of oversize fetuses (mass $>3$ so heavier than control mean) was: co-culture, $20.0 \%(4 / 20)$; SOF-, $0 \%$; and SOF+, $0 \%$. The masses of these oversized co-culture fetuses were significantly greater $(105.0 \pm 3.8 \mathrm{~g}, n=4, p<0.001)$ than the control mean $(74.2 \pm$ $1.7 \mathrm{~g}$ ). The magnitude of the shift in organ development for these fetuses is illustrated (Table 5) and the mean organ masses predicted from the allometric equations of Sinclair et al. (1998) (normal allometric growth) are compared with those predicted from the co-culture equations using, in both cases, the observed co-culture fetal masses, which were > 3 SD above the mean of control fetuses. This analysis allowed treatment effects on organ mass to be compared in the absence of the confounding effects of fetal mass, and 
Table 3. Organ and muscle masses, and humerus length (means \pm SEM) for Suffolk $\times$ Scottish Blackface sheep fetuses recovered at day 61 of gestation

\begin{tabular}{lcccc}
\hline & Co-culture & SOF- & SOF+ & Control \\
\hline Number & 20 & 27 & 25 & 25 \\
Liver (g) & $6.91 \pm 0.37^{\mathrm{b}}$ & $5.96 \pm 0.23^{\mathrm{a}}$ & $6.19 \pm 0.26^{\mathrm{ab}}$ & $5.50 \pm 0.16^{\mathrm{a}}$ \\
Heart (g) & $0.831 \pm 0.057^{\mathrm{b}}$ & $0.628 \pm 0.027^{\mathrm{a}}$ & $0.667 \pm 0.033^{\mathrm{a}}$ & $0.605 \pm 0.024^{\mathrm{a}}$ \\
Kidneys (g) & $1.25 \pm 0.08^{\mathrm{b}}$ & $1.10 \pm 0.04^{\mathrm{ab}}$ & $1.20 \pm 0.08^{\mathrm{b}}$ & $0.98 \pm 0.03^{\mathrm{a}}$ \\
Humerus (mm) & $16.8 \pm 0.7^{\mathrm{a}}$ & $15.4 \pm 0.3^{\mathrm{ab}}$ & $14.9 \pm 0.3^{\mathrm{b}}$ & $15.9 \pm 0.4^{\mathrm{ab}}$ \\
Plantaris (mg) & $36.2 \pm 2.4^{\mathrm{b}}$ & $29.4 \pm 1.6^{\mathrm{a}}$ & $28.1 \pm 1.6^{\mathrm{a}}$ & $30.8 \pm 1.3^{\mathrm{a}}$ \\
Tibialis anterior (mg) & $55.3 \pm 2.7^{\mathrm{b}}$ & $39.2 \pm 2.6^{\mathrm{ac}}$ & $36.6 \pm 2.2^{\mathrm{c}}$ & $44.7 \pm 2.1^{\mathrm{a}}$ \\
\hline
\end{tabular}

Means with different superscripts within rows are significantly different $(P<0.05)$.

For description of treatments, see Table 1.

SOF-: synthetic oviductal fluid medium without serum; SOF+: synthetic oviductal fluid medium supplemented with human serum.

Table 4. Allometric coefficients ( $b \pm \mathrm{SEM}$ ) relating organ or muscle tissue mass, or humerus length to fetal mass at day 61 of gestation (from the equation $\log _{c} y=\log _{e} a+b \log _{e} x$, where $y=$ organ mass and $x=$ fetal mass) for Suffolk $\times$ Scottish Blackface sheep fetuses

\begin{tabular}{lcccc}
\hline & Co-culture & SOF- & SOF+ & Control \\
\hline Number & 20 & 27 & 25 & 25 \\
Liver $(g)$ & $1.379 \pm 0.199^{\mathrm{bc}}$ & $0.850 \pm 0.204^{\mathrm{ab}}$ & $1.442 \pm 0.183^{\mathrm{c}}$ & $0.773 \pm 0.183^{\mathrm{a}}$ \\
Heart (g) & $1.700 \pm 0.246^{\mathrm{b}}$ & $0.982 \pm 0.226^{\mathrm{a}}$ & $1.537 \pm 0.235^{\mathrm{ab}}$ & $1.042 \pm 0.229^{\mathrm{a}}$ \\
Kidneys (g) & $1.547 \pm 0.195^{\mathrm{b}}$ & $0.807 \pm 0.214^{\mathrm{a}}$ & $1.306 \pm 0.347^{\mathrm{ab}}$ & $0.984 \pm 0.199^{\mathrm{a}}$ \\
Humerus (mm) & $0.757 \pm 0.261$ & $0.230 \pm 0.142$ & $0.309 \pm 0.137$ & $0.537 \pm 0.209$ \\
Plantaris (mg) & $1.832 \pm 0.307^{\mathrm{b}}$ & $1.119 \pm 0.331^{\mathrm{a}}$ & $1.497 \pm 0.378^{\mathrm{ab}}$ & $0.921 \pm 0.349^{\mathrm{a}}$ \\
Tibialis anterior (mg) & $1.297 \pm 0.314$ & $0.882 \pm 0.506$ & $1.884 \pm 0.519$ & $1.106 \pm 0.367$ \\
\hline
\end{tabular}

Means with different superscripts within rows are significantly different $(P<0.05)$.

For description of treatments, see Table 1.

SOF-: synthetic oviductal fluid medium without serum; SOF+: synthetic oviductal fluid medium supplemented with human serum.

indicated that organ masses of oversized fetuses were greater than predicted and that organ development had been fundamentally altered.

At day 125 of gestation, both the gravid uterus and chorioallantois were significantly heavier for the co-culture and SOF+ treatments than they were for the control and SOF- treatments $(P<0.05$; Table 6$)$. Mean conceptus fluid mass was significantly greater $(P<0.01)$ for the co-culture treatment than for the other treatments. The mass of fluid for three conceptuses $(3 / 13$ or $23 \%)$ from this treatment was $>3 \mathrm{SD}$ above the mean of the control treatment. The mass of fluid for five conceptuses (5/13 or $38 \%$ ) from the same treatment was greater than that for the heaviest conceptus from the control treatment. Fetuses derived from the co-culture treatment were, on average, $1121 \mathrm{~g}$ or $34 \%$ heavier $(P<0.001)$, and $47 \mathrm{~mm}$ or $9 \%$ longer $(P<0.001)$ than fetuses from the control treatment. Fetuses derived from the SOF+ treatment were $585 \mathrm{~g}$ heavier $(18 \% ; P<0.05)$, and were associated with a larger chorioallantois $(P<0.05)$ and total gravid uterus mass $(P<0.05)$ than fetuses derived from the control treatment. There was a weak but significant $(r=0.55 ; P<0.01)$ correlation between cotyledon mass and the mass of fetuses derived from embryos cultured in each of the three in vitro systems.

All organ and muscle masses, and humerus lengths at day 125 of gestation were greater $(P<0.001)$ for fetuses derived from the co-culture treatment than those from the control treatment (Table 7). Both liver and kidney masses were greater $(P<0.05)$ for co-culture and $\mathrm{SOF}+$ fetuses than controls. The number of fetuses recovered from the three culture treatments at this time point were too few to establish meaningful allometric relationships within culture treatment. By combining data from the co-culture and SOF+ treatments, however, allometric coefficients (mean \pm SEM) of $1.203 \pm$ 0.213 and $1.461 \pm 0.280$ were obtained for fetal liver and heart at this stage of gestation. These coefficients, together with those obtained at day 61 of gestation were significantly greater $(\mathrm{P}<0.05)$ than those of 0.850 and 0.921 established for liver and heart respectively in normally developing fetuses between day 60 and day 135 of gestation in the study of Sinclair et al. (1998).

The incidence of oversized fetuses at day 125 of gestation, defined as those heavier than the control mean plus $3 \mathrm{SD}$, was: co-culture, $69.2 \%(9 / 13)$; SOF-, $0 \%$; and SOF+, $16.7 \%$ $(1 / 6)$. The mean mass of the oversized fetuses on the basis of this criterion was significantly greater $(4623 \pm 193 \mathrm{~g}$, $n=10, P<0.001)$ than the control mean $(3282 \pm 65 \mathrm{~g})$. The magnitude of the shift in the development of key organs was predicted from the observed fetal masses of co-culture and $\mathrm{SOF}+$ treatments using the combined allometric equation for those treatments and comparing the data with those predicted from the allometric equations of Sinclair et al. (1998) for fetuses derived from in vivo produced embryos (Table 8). This analysis allowed treatment effects on organ size to be compared in the absence of confounding effects of 



Fig. 1. Differential growth of the sheep fetal liver (a) and heart (b) at day 61 of gestation after in vitro embryo culture. Allometric plots for fetuses derived from embryos co-cultured in the presence of bovine granulosa cells (co-culture; $\bullet$ ); and cultured in a synthetic oviductal fluid medium with added serum ( $\mathrm{SOF}+$; 0 ). Control fetuses are represented by the solid lines. Points $A$ and $B$ represent the minimum and maximum masses, respectively, of control fetuses at this stage of gestation.

fetal mass and, as for day 61, organ masses of oversized fetuses were greater than those expected had these fetuses been developing normally.

\section{Discussion}

The results from this study clearly indicate that the system of in vitro embryo culture can significantly influence both fetal growth and development. In vivo derived sheep zygotes cultured in the presence of bovine granulosa cells or in a synthetic oviductal fluid medium with added serum gave rise to a number of fetuses that were significantly larger than those derived from in vivo produced embryos or zygotes cultured in a synthetic oviductal fluid medium with no added serum. Moreover, these differences in size were proportionally greater at day 125 of gestation than at day 61 , indicating a divergent growth pattern arising from treatment differences in specific growth during early fetal life. Larger fetuses exhibited altered development and, on occasion, were associated with excessive volumes of amniotic fluid (polyhydramnios). Therefore, these findings are consistent with those of others who showed that in vitro embryo culture significantly affects fetal growth and birth mass in both cattle (for example, Behboodi et al., 1995; Farin and Farin, 1995; Hasler et al., 1995) and sheep (for example, Thompson et al., 1995; Holm et al., 1996; Brown and Radziewic, 1998), but add to these observations by showing that the fundamental patterns of organ and tissue development have also been altered.

The present study has provided a formal mathematical description of alterations in organ and tissue development for fetuses derived from in vitro produced embryos. Furthermore, this study is the first demonstration, to our knowledge, of any in vitro embryo culture treatment creating an increase in the allometric relationships of key organs and tissues to the whole animal. Organs and tissues grow differentially during normal development. Thus, simple ratios of organ:fetal mass provide little indication of alterations in fetal development because such ratios change during the normal growth process. Consequently, the calculation of these ratios or simple adjustments for body weight, as in previous studies (for example, Farin et al., 1997; Hartwich et al., 1997), are inappropriate indicators of changes in fetal development. In contrast, allometry implicitly recognizes that the ratio of the component to the whole inevitably changes as the fetus grows and, therefore, provides a means of assessing whether the ratio is equal to, or different from, the expected ratio at the observed mass. The data presented here clearly demonstrate that this ratio was profoundly altered in co-culture compared with control fetuses at day 61 of gestation for the key organs, liver and heart, and that these differences were still present and significant at day 125 of gestation. Moreover, these effects were more pronounced for those fetuses classified as oversize than for fetuses of average mass.

It is generally accepted that shifts in the development of fetal organs and tissues can only be observed in the most extreme circumstances (Everitt, 1968); and even then, apart from the liver which is highly responsive to transitory shifts in nutritional status, other organs and structural components of body show only minor shifts in their allometric growth coefficients (Robinson, 1981).

Allometric coefficients established for each of the visceral organs and muscle tissues recovered from fetuses derived from co-cultured embryos indicate that their development was altered. Large fetuses from this treatment group had disproportionately large visceral organs and muscles. Histological examination of the fetal plantaris muscle at days 61 and 125 of gestation in the present study (Maxfield et al., 1998) showed that the increased muscle development arising from co-culturing embryos with granulosa cells was due to an increase in primary muscle fibre hypertrophy and an increase in secondary muscle fibre hyperplasia and hypertrophy, resulting in increases in the secondary:primary muscle fibre ratio and muscle mass.

A similar picture is apparent for fetuses derived from embryos that were cultured in synthetic oviductal fluid with added serum. Although the effect of this treatment was 
Table 5. Expected versus actual organ masses for Suffolk $\times$ Scottish Blackface sheep fetuses derived from co-cultured embryos at day 61 of gestation

\begin{tabular}{|c|c|c|c|c|c|}
\hline & \multirow[b]{2}{*}{$n$} & \multicolumn{2}{|c|}{ Organ mass (g) } & \multirow[b]{2}{*}{ SED } & \multirow[b]{2}{*}{ Significance } \\
\hline & & Expected $^{2}$ & Actual $^{3}$ & & \\
\hline \multicolumn{6}{|c|}{ Co-culture fetal masses $>$ control mean ${ }^{4}+3 \mathrm{SD}$ : } \\
\hline Liver & 4 & 8.62 & 10.16 & 0.28 & $P<0.01$ \\
\hline Heart & 4 & 1.030 & 1.167 & 0.039 & $P<0.05$ \\
\hline
\end{tabular}

The expected values are based on the allometric relationships of Sinclair $\mathfrak{c t}$ al. (1998) (normal allometric growth) and the actual values are based on allometric relationships obtained from fetuses derived from co-culture embryos in the present study. 'Paired $t$ test; ${ }^{2}$ control (Sinclair et al., 1998) allometric equations ( $y=$ organ mass; $x=$ fetal mass) were liver, $\log _{i} y=-2.17+0.857 \log x$; heart, $\log _{i} y=-4.30+0.922 \log _{i} x ;{ }^{3}$ co-culture allometric equations ( $y=$ organ mass; $x=$ fetal mass) were $\operatorname{liver} \log _{c} y=-4.10+1.379$ $\log _{r} x$; heart, $y=-7.76+1.70 \log x ;{ }^{4}$ control: masses of fetuses derived from in vivo produced embryos in present experiment.

Table 6. Products of conception (mean \pm SEM) at day 125 of gestation for Suffolk $\times$ Scottish Blackface sheep fetuses derived from day 6 in vivo produced embryos (control) or day 6 in vitro produced embryos from in vivo produced zygotes

\begin{tabular}{lcccc}
\hline & Co-culture & SOF- & SOF+ & Control \\
\hline Number & 13 & 8 & 6 & 22 \\
Gravid uterus $(g)$ & $8230 \pm 426^{\mathrm{c}}$ & $6274 \pm 179^{\mathrm{a}}$ & $7205 \pm 372^{\mathrm{b}}$ & $6056 \pm 132^{\mathrm{a}}$ \\
Fluids $(\mathrm{g})$ & $2268 \pm 321^{\mathrm{b}}$ & $1369 \pm 114^{\mathrm{a}}$ & $1266 \pm 101^{\mathrm{a}}$ & $1454 \pm 88^{\mathrm{a}}$ \\
Chorioallantois* $\left.^{*} \mathrm{~g}\right)$ & $905 \pm 54^{\mathrm{b}}$ & $720 \pm 78^{\mathrm{a}}$ & $932 \pm 88^{\mathrm{b}}$ & $637 \pm 29^{\mathrm{a}}$ \\
Uterus + caruncles $(\mathrm{g})_{\text {Fetal mass }(\mathrm{g})}^{717 \pm 22}$ & $736 \pm 41$ & $728 \pm 50$ & $678 \pm 17$ \\
Fetal CRL $(\mathrm{mm})$ & $4403 \pm 180^{\mathrm{c}}$ & $3454 \pm 127^{\mathrm{ab}}$ & $3867 \pm 164^{\mathrm{b}}$ & $3282 \pm 65^{\mathrm{a}}$ \\
\hline
\end{tabular}

Means with different superscripts within rows are significantly different $(P<0.05)$

*Includes amnion.

For description of treatments, see Table 1 .

SOF-: synthetic oviductal fluid medium without serum; SOF+: synthetic oviductal fluid medium supplemented with human serum; CRL: curved crown-rump length.

Table 7. Organ and muscle masses, and humerus length (means \pm SEM) for Suffolk $\times$ Scottish Blackface sheep fetuses recovered at day 125 of gestation

\begin{tabular}{lcccc}
\hline & Co-culture & SOF- & SOF + & Control \\
\hline Number & 13 & 8 & 6 & 22 \\
Liver $(\mathrm{g})$ & $139.6 \pm 7.4^{\mathrm{b}}$ & $115.9 \pm 8.7^{\mathrm{ac}}$ & $135.5 \pm 10.6^{\mathrm{bc}}$ & $107.5 \pm 4.5^{\mathrm{a}}$ \\
Heart (g) & $35.6 \pm 2.4^{\mathrm{b}}$ & $20.7 \pm 1.8^{\mathrm{a}}$ & $25.8 \pm 1.9^{\mathrm{a}}$ & $24.6 \pm 1.3^{\mathrm{a}}$ \\
Kidneys (g) & $34.8 \pm 2.9^{\mathrm{b}}$ & $22.7 \pm 3.1^{\mathrm{ac}}$ & $29.8 \pm 3.2^{\mathrm{bc}}$ & $20.0 \pm 0.7^{\mathrm{a}}$ \\
Humerus $(\mathrm{mm})^{*}$ & $80.8 \pm 1.2^{\mathrm{b}}$ & - & - & $72.8 \pm 1.1^{\mathrm{a}}$ \\
Plantaris $(\mathrm{g})$ & $3.67 \pm 0.35^{\mathrm{b}}$ & $2.64 \pm 0.11^{\mathrm{a}}$ & $2.71 \pm 0.13^{\mathrm{a}}$ & $2.42 \pm 0.09^{\mathrm{a}}$ \\
Tibialis anterior $(\mathrm{g})$ & $5.35 \pm 0.37^{\mathrm{b}}$ & $3.97 \pm 0.27^{\mathrm{a}}$ & $4.11 \pm 0.11^{\mathrm{a}}$ & $3.88 \pm 0.13^{\mathrm{a}}$ \\
\hline
\end{tabular}

Means with different superscripts within rows are significantly different $(P<0.05)$.

* Samples restricted to control and co-culture treatments.

For description of treatments, see Table 1.

SOF-: synthetic oviductal fluid medium without serum; SOF+: synthetic oviductal fluid medium supplemented with human serum.

statistically significant only for fetal liver at day 61 of gestation, significant differences existed for both liver and heart at day 125 of gestation when allometric coefficients for these organs were compared to those established by Sinclair et al. (1998). The allometric lines at day 61 for fetuses derived from co-cultured embryos and embryos that were cultured in synthetic oviductal fluid with added serum were virtually identical, but gradient coefficients were significantly greater than those for fetuses developing normally. This means that, in the absence of significant differences in fetal size at day 61 of gestation, significant differences in fetal development were detectable between control fetuses and those derived from embryos cultured in synthetic oviductal fluid with added serum. Given the central role of the viscera in supporting the metabolic requirements of growth, it is possible that deviations in the development of key organs during early fetal life may have a bearing on growth during later fetal life. 
Table 8. Expected versus actual organ masses for Suffolk $\times$ Scottish Blackface sheep fetuses derived from in vitro produced embryos (co-culture and synthetic oviductal fluid medium plus serum $(\mathrm{SOF}+)$ ) at day 125 of gestation

\begin{tabular}{|c|c|c|c|c|c|}
\hline & \multirow[b]{2}{*}{$n$} & \multicolumn{2}{|c|}{ Organ mass (g) } & \multirow[b]{2}{*}{ SED } & \multirow[b]{2}{*}{ Significance $^{1}$} \\
\hline & & Expected $^{2}$ & Actual $^{3}$ & & \\
\hline \multicolumn{6}{|c|}{ Co-culture fetal masses $>$ control mean ${ }^{4}+3 \mathrm{sD}:$} \\
\hline Liver & 10 & 139.4 & 151.2 & 3.51 & $P<0.01$ \\
\hline Heart & 10 & 32.2 & 36.1 & 1.07 & $P<0.01$ \\
\hline
\end{tabular}

The expected values are based on the allometric relationships of Sinclair et al. (1998) (normal allometric growth) and the actual values are based on allometric relationships obtained from fetuses derived from co-culture and $\mathrm{SOF}+$ embryos in the current study. 'Paired $t$ test; ${ }^{2}$ control (Sinclair et al., 1998) allometric equations ( $y=$ organ mass; $x=$ fetal mass) were liver, $\log y=-1.27+0.736 \log , x$; heart, $\log _{i} y=-4.20+0.909 \log _{i} x ;{ }^{3}$ in vitro allometric equations $\left(y=\right.$ organ mass; $x=$ fetal mass) were liver, $\log _{,} y=-5.11+1.20 \log , x$; heart, $\log _{4} y=-8.74+1.46 \log _{i} x ;{ }^{4}$ control: masses of fetuses derived from $i n$ vivo produced embryos in present experiment.

There have been previous reports of gross abnormalities, albeit at a relatively low frequency, of several key organs and tissues following in vitro embryo culture, including head and limb deformities (Walker et al., 1992b) and cerebellar dysplasia (Schmidt et al., 1996). Although only 2/35 calves born as a consequence of in vitro embryo culture and transfer showed any signs of gross abnormalities in the study of Van Soom et al. (1994), it is perhaps noteworthy that these abnormalities included a ventricular septum defect and a cirrhotic liver.

In contrast to the systems discussed above, allometric coefficients established for the same organs and tissues in control fetuses and those derived from embryos cultured in synthetic oviductal fluid with no added serum are in close agreement with those established for normally growing and developing fetuses of the same genotype in the study of Sinclair et al. (1998), and with those established in the early observations on fetal growth made by Wallace (1948). This comparison implies that development was normal for the SOF- fetuses in the present study, thus supporting earlier observations that lamb birth weight and the incidence of developmental abnormalities are not increased when zygotes are cultured in synthetic oviductal fluid supplemented with bovine serum albumin and amino acids only (Walker et al., 1992a; Thompson et al., 1995). While such semi-defined culture systems may avoid the problem of aberrant fetal growth and development, the lower blastocyst yields and pregnancy rates reported by these authors and observed in the present study need to be improved for commercial application. It is necessary to ensure that such improvements are not accompanied by perturbations of growth and development in some of the fetuses produced. However, the incidence and severity of fetal oversize observed after the transfer of embryos produced in $\mathrm{co}^{-}$culture or $\mathrm{SOF}+$ systems were of such magnitude as would make their use in practice inadvisable on ethical and welfare grounds.

A further observation from the present study was the high incidence of polyhydramnios $(\geq 23 \%$ ) in conceptuses derived from co-cultured embryos. The frequency with which this condition appears naturally in sheep is unknown but, in cattle, Hasler et al. (1995) reported a natural incidence of 1 per 7500 calvings, and an increased incidence to 1 per 200 calvings in calves derived from in vitro produced embryos. In humans, the natural incidence of polyhydramnios is higher at around $1 \%$ and is normally associated with pregnancies complicated by maternal diabetes mellitus or congenital anomalies involving the gastrointestinal tract, central nervous and cardiovascular systems, and the urinary tract (Moise, 1997). The mechanisms that produce such fluid imbalances are not known, but the condition is associated with fetal hypoxia and increased fetal lactate which, in sheep, has been shown to act as a powerful osmotic agent for the accumulation of fluid from the maternal compartment by the conceptus (Powell and Brace, 1991). Since placental size in sheep reaches a plateau towards the end of the second third of pregnancy (Robinson et al., 1977) and, as the present data show, large fetuses from embryo culture do not necessarily have large placentae, it is postulated that precocious fetal growth during the final trimester of pregnancy may induce fetal hypoxia and an associated increase in fetal plasma lactate concentrations, which are predisposing conditions for the development of polyhydramnios.

The mechanisms which cause these marked changes in growth and development in the fetal oversize syndrome are the subject of much speculation and have been reviewed recently (Walker et al., 1996; Farin and Farin, 1997; Young et al., 1998). Candidate perturbing agents and/or facilitating factors include ammonia (Lane and Gardner, 1994; McEvoy et al., 1997), progesterone (Kleemann et al., 1994; Carolan et al., 1997) and growth factors (Watson et al., 1992, 1994) which may be provided by serum or granulosa cells. Ammonia, or ammonium, and growth factors are potential causative agents in the present study although some role for progesterone cannot be overlooked because of its presence, and promotion by serum growth factors, in the co-culture system (Kuran et al., 1996). It is believed that the causative agent(s) alter(s) the expression of a gene or genes associated with growth and development. Imprinted genes, including H19, Igf2, Igf $2 \mathrm{r}$ and Insulin-2, have been identified as candidates for this role due to their involvement in early embryo development (Leighton et al., 1996) and because similar phenotypes to those observed in the present study exist in both humans and mice when expression of such genes has been altered (Young et al., 1998). Their role, however, remains to be confirmed since patterns of imprinting have not been established in ruminant embryos.

In the present experiment, predicted mean birth weights (from the data of Sinclair et al., 1998) were approximately 6 
$\mathrm{kg}$ for control and $8 \mathrm{~kg}$ for co-culture and SOF+ treatments, with the heaviest lamb from these treatments predicted to be about $9 \mathrm{~kg}$ at birth. However, these predictions for lambs derived from cultured embryos are underestimates because specific growth rates appropriate to controls were used to calculate all the birth weights whereas fetuses on the culture treatments had higher specific growth rates that could not be quantified. All fetuses heavier than the control mean plus $3 \mathrm{SD}$ would probably have required a Caesarean delivery and this proportion $(52.6 \%, 10 / 19)$ is similar to that observed by Goodhand et al. (1997) for the delivery of calves $(46.0 \%$, $12 / 26$ ) derived from in vitro embryos produced using the coculture system described here.

The long-term effects of perturbed fetal growth and development have not been reported but, in the medium term, at about 1 year of age, both lambs and calves that are oversize at birth have similar weights to those with normal birth weights (Wilson et al., 1995; Walker et al., 1996; McEvoy et al., 1998). However, McEvoy et al. (1998) showed that oversized calves produced from in vitro co-cultured embryos had abnormally large hearts compared with their control counterparts when killed at the same weight at about 13 months of age. In view of the extent and degree of the prenatal and perinatal problems associated with the fetal oversize syndrome, it is probable that there are some consequences for the long term health, well-being, welfare, productivity and life span of the animal that would be of profound significance if they occurred in human subjects (Barker and Clark, 1997) born as a consequence of assisted reproductive technologies.

In conclusion, this work extends the observation that the presence of serum (SOF+) or somatic cells (co-culture), but not their absence (SOF-), during the in vitro culture of embryos influences fetal growth. It demonstrates that oversized fetuses recovered during late gestation arise as a consequence of a divergent growth pattern, due to treatment differences in specific growth rate during early fetal life. Furthermore, this study provides the first formal evidence of altered fetal development in fetuses arising from embryo culture as demonstrated by deviations in allometric relationships between organ and fetal masses. The sporadic occurrence of this problem has made it difficult to study (Farin and Farin, 1997; Young et al., 1998). However, the coculture and SOF+ systems in the present study provide robust, repeatable and relatively efficient models for the study of the fetal oversize syndrome.

The authors gratefully acknowledge the skilled technical assistance provided by D. F. Dolman, M. E. Staines, M. J. Ranilla, D. J. Kyle, M. E. King and R. G. Watt. Animal supervision was provided by J. C. Rae and staff. Financial support was received from the Ministry of Agriculture, Fisheries and Food, and the Scottish Office, Agriculture, Environment and Fisheries Department.

\section{References}

Barker DJP and Clark PM (1997) Fetal undernutrition and disease in later life Reviezus of Reproduction 2 105-112

Behboodi E, Anderson GB, BonDurant RH, Cargill SL, Kreuscher BR, Medrano JF and Murray JD (1995) Birth of large calves that developed from in vitro derived bovine embryos Theriogenology 44 227-232

Brash LD, Wray NR and Goddard ME (1996) Use of MOET in Merino breeding programmes: a practical and economic appraisal Animal Science 62 $241-254$

Brown BW and Radziewic T (1998) Production of sheep embryos in vitro and development of progeny following single and twin embryo transfers Theriogenology 49 1525-1536

Carolan C, McEvoy TG, Gebbie FE, Sinclair KD, Robinson JJ and Broadbent PJ (1997) Steer sera from different nutritional backgrounds alter ammonia and progesterone concentrations in a bovine granulosa cell culture system Journal of Reproduction and Fertility Abstract Series 19126

Everitt GC (1968) Prenatal development of uniparous animals with particular reference to the influence of maternal nutrition in sheep. In Growth and Development of Mammals pp 131-157 Eds GA Lodge and GE Lamming. Butterworths, London

Farin PW and Farin CE (1995) Transfer of bovine embryos produced in vivo or in vitro: survival and fetal development Biology of Reproduction 52 676-682

Farin PW and Farin CE (1997) Perspectives on large calves following transfer of embryos produced in vitro. IETS Embryo Transfer Newoletter 15 15-19

Farin PW, Farin CE and Mungal SA (1997) Measurements of bovine fetuses and placentas at 63 days after transfer of embryos produced in vivo or in vitro. Theriogenology 47319 (Abstract)

Garry FB, Adams R, McCann JP and Odde KG (1996) Postnatal characteristics of calves produced by nuclear transfer cloning Theriogenology $45141-152$

Genstat 5 Committee (1993) Genstat 5 Release 3 Reference Manual Oxford Science Publications, Clarenden Press, Oxford

Goodhand KL, Dolman DF, Watt RG, Higgins LC, Staines ME and Broadbent PJ (1997) Calving outcome following transfer of in vivo and in vitro produced bovine embryos Proceedings of the British Socity of Animal Science 34

Hartwich KM, Kleeman DO, Seamark RF and Walker SK (1997) Fetal development in the sheep following manipulation of the embryo or its environment Theriogenology 47322 (Abstract)

Hasler JF, Henderson WB, Hurtgen PJ, Jin ZQ, McCauley AD, Mower SA, Neely B, Shuey S, Stokes JE and Trimmer SA (1995) Production, freezing and transfer of bovine IVF embryos and subsequent calving results Theriogenology 43 141-152

Holm P, Walker SK and Seamark RF (1996) Embryo viability, duration of gestation and birth weight in sheep after transfer of in vitro matured and in vitro fertilized zygotes cultured in vitro or in vivo. Journal of Reproduction and Fertility 107 175-181

Huxley JS (1932) Problems of Relative Growth Methuen, London

Kleemann DO, Walker SK and Seamark RF (1994) Enhanced fetal growth in sheep administered progesterone during the first three days of pregnancy Journal of Reproduction and Fertility 102 411-417

Kruip ThAM and den Daas JHG (1997) in vitro produced and cloned embryos: effects on pregnancy, parturition and offspring Theriogenology 47 $43-52$

Kuran M, Hutchinson JSM and Broadbent PJ (1996) The response of bovine granulosa cells to different gonadotrophins in culture Animal Reproduction Science 45 1-12

Lane M and Gardner DK (1994) Amino acids increase post-implantation development of cultured mouse embryos while ammonium induces exencephaly and fetal retardation journal of Reproduction and Fertility 102 305-312

Leighton PA, Saam JR, Ingram RS and Tilghman SM (1996) Genomic imprinting in mice: its function and mechanism Biology of Reproduction $\mathbf{5 4}$ 273-278

Lindner GM and Wright RW, Jr (1983) Bovine embryo morphology and evaluation Theriogenology 20 407-416

McEvoy TG, Robinson JJ, Aitken RP, Findlay PA and Robertson IS (1997) Dietary excesses of urea influence the viability and metabolism of preimplantation sheep embryos and may affect fetal growth among survivors Animal Reproduction Science 47 71-90

McEvoy TG, Sinclair KD, Goodhand KL, Broadbent PJ and Robinson JJ (1998) Post-natal development of Simmental calves derived from in vivo or in vitro embryos Gametes: Development and Function p 573 Eds A Lauria, F Gandolfi, G Enne and L Gianaroli. Tabloid S.r.l, Rome

McMillan WH and Hall DRH (1994) Laparoscopic transfer of ovine and cervine embryos using the transpic technique Theriogenology 42 137-146

Maxfield EK, Sinclair KD, Broadbent PJ, McEvoy TG, Robinson JJ and Maltin CA (1998) Short term culture of ovine embryos modifies fetal 
myogenesis Ancrican Journal of Physiology 274 (Endocrinology and Metabolism 37) E1121-E1123

Moise KJ, Jr (1997) Polyhydramnios Clinical Obstetrics and Gynecology 40 266-279

Powell TL and Brace RA (1991) Elevated fetal plasma lactate produces polyhydramnios in the sheep American Journal of Obstetrics and Gynecology 165 1595-1607

Robinson JJ (1981) Prenatal growth and development in the sheep and its implications for the viability of the newborn lamb Livestock Production Science 8 273-281

Robinson JJ, McDonald I, Fraser C and Crofts RMJ (1977) Studies on reproduction in prolific ewes I. Growth of the products of conception Journal of Agricultural Science Cambridge 88 539-552

Schmidt M, Greve T, Avery B, Beckers JF, Sulon J and Hansen HB (1996) Pregnancies, calves and calf viability after transfer of in vitro produced bovine embryos Theriogenology 46 527-539

Sinclair KD and Broadbent PJ (1996) Increasing the efficiency of suckled calf production using embryo transfer technology Veterinary Record 139 409-412

Sinclair KD, Dunne LD, Maxfield EK, Maltin CA, Young LE, Wilmut I, Robinson JJ and Broadbent PJ (1998) Fetal growth and development following temporary exposure of day 3 ovine embryos to an advanced uterine environment Reproduction, Fertility and Development $10263-269$

Tervit HR, Whittingham DG and Rowson LEA (1972) Successful culture in vitro of sheep and cattle ova Journal of Reproduction and Fertility 30 493-497

Thompson JG, Gardner DK, Pugh A, McMillan WH and Tervit HR (1995) Lamb birth weight is affected by culture system utilized during in vitro preelongation development of ovine embryos Biology of Reproduction 53 1385-1391

Van Soom A, Mijten P, Van Vlaenderen I, Van den Branden J, Mahmoudzadeh AR and de Kruif A (1994) Birth of double-muscled Belgian Blue calves after transfer of in vitro produced embryos into dairy cattle Theriogenology 41 855-867

van Wagtendonk-de Leeuw AM, Aerts BJG and den Daas JHG (1998) Abnormal offspring following in vitro production of bovine preimplantation embryos: a field study Theriogenology 49 883-894
Walker SK, Heard TM and Seamark RF (1992a) In vitro culture of sheep embryos without co-culture: success and perspectives Theriogenology 37 $111-126$

Walker SK, Heard TM, Bee CA, Frensham AB, Warnes DM and Seamark RF (1992b) Culture of embryos of farm animals. In Embryonic Development and Manipulation in Animal Production pp 77-92 Eds A Lauria and F Gandolfi. Portland Press Ltd, London

Walker SK, Hartwich KM and Seamark RF (1996) The production of unusually large offspring following embryo manipulation: concepts and challenges Theriogenology $45111-120$

Wallace LR (1948) The growth of lambs before and after birth in relation to the level of nutrition Journal of Agricultural Science Cambridge 38 92-153; 367-401

Watson AJ, Hogan A, Hahnel A, Weimer KE and Scultz GA (1992) Expression of growth factor ligand and receptor genes in the preimplantation bovine embryo Molecular Reproduction and Development 31 87-95

Watson AJ, Watson PH, Arcellana-Panlilo M, Warnes D, Walker S, Schultz GA, Armstrong DT and Seamark RF (1994) A growth factor phenotype map for ovine preimplantation development Biology of Reproduction $\mathbf{5 0}$ $725-733$

Wilmut I and Whitelaw CBA (1994) Strategies for production of pharmaceutical proteins in milk Reproduction, Fertility and Development 6 $625-630$

Wilson JM, Williams JD, Bondioli KR, Looney CR, Westhusin ME and McCalla DF (1995) Comparison of birth weight and growth characteristics of bovine calves produced by nuclear transfer (cloning), embryo transfer and natural mating Animal Reproduction Science 38 73-83

Willadsen SM, Janzen RE, McAlister RJ, Shea BF, Hamilton G and McDermand D (1991) The viability of late morulae and blastocysts produced by nuclear transplantation in cattle Theriogenology 35 161-170

Woolliams JA and Wilmut I (1989) Embryo manipulation in cattle breeding and production Animal Production 49 3-30

Young LE, Sinclair KD and Wilmut I (1998) Large offspring syndrome in cattle and sheep Reviews of Reproduction 3 155-163 